\title{
The Process of Political Decision-Making in Groups
}

\author{
Search Behavior and Choice Shifts
}

\author{
SAMUEL A. KIRKPATRICK \\ DWIGHT F. DAVIS \\ ROBY D. ROBERTSON \\ University of Oklahoma
}

A substantial portion of public policy is created, implemented, and adjudicated through small groups of elective and appointive officials occupying various institutional roles in the United States. A thorough understanding of the decision-making process is crucial if we are to comprehend policy-making and resultant policy outcomes. Small group decision-making bodies characterize local, state, and national political systems in both domestic and foreign policy arenás. Yet the small group process and the social-psychological mechanisms influencing individual and collective choice resulting from that process are considerably under-investigated in the examination of policy systems.

Our purpose is to explicate a theoretical framework which specifically addresses microanalytic components of the process of political decisionmaking. Although an extensive and critical review of the epistemological, practical, and theoretical problems of decision-making and the literature relevant to them has already been addressed in some detail elsewhere (Kirkpatrick, 1975a; 1975c), our approach to decision-making is guided by a number of general assumptions. These include the premise that social-psychological concepts used in political science have enjoyed little

AMERICAN BEHAVIORAL SCIENTIST, Vol. 20 No. 1, September/October 1976 (C) 1976 Sage Publications, Inc. 
direct application to the study of decision-making; that political science decision-making students have generally avoided social-psychological concepts beyond early works; that psychologists interested in decision-making are more akin to their "rational man" economic colleagues than to social psychologists; and that relevant social psychologists most familiar with use ful concepts have generally avoided the topic of decision-making. These premises are complemented by an unproductive tendency to study decision-making as a series of discrete units of behavior (see Scioli et al., 1971). Furthermore, political scientists have not systematically linked psychological and environmental variables, and research tends to emphasize either the organization, the decision-maker, or the decisional outcome.

\section{DECISION PROCESS COMPONENTS: ALTERNATIVE SEARCH AND CHOICE SHIFT}

The most fundamental subprocesses of decision-making include the search for alternatives and the shifting of choices dependent upon the assessment of consequences. A nagging difficulty for political decisionmaking scholars has been the problem of theoretically linking decisional processes and outcomes or policy decisions. While recognizing that decision-making involves some set of functional behaviors (e.g., problem recognition, alternative generation, bargaining), decision-making theorists have generally been unable to develop testable and specific propositions concerning the impact of decisional processes on final choices.

The above problem appears to result from an unnecessary dichotomization of the analytical possibilities available for explaining decisions. Traditionally, the approaches open to the analyst appear to be between those which promise theoretical generality for explaining decisional outcomes at the cost of obscuring decisional processes, and approaches which are rich in process analysis, but idiosyncratic or illusory in terms of explaining outcomes. Examples of the first set of approaches include many at tempts to explain decisions in terms of rational choice wherein a variety of process factors are either ignored or "assumed away" (Arrow, 1963: Downs, 1957; Riker and Ordershook, 1973; see review by Hofferbert, 1972). Examples of the second set of approaches include historical case analyses of specific decisions (Snyder et al., 1962; for discussion see Roig, 1973; Robinson and Majak, 1967), and an array of social-psychological models which exclude outcomes (see reviews by Kirkpatrick, 1975c, and 
Holsti, 1976). Decision-making scholars need not be limited to choices within this traditional dichotomy, especially with respect to the analysis of political decision-making by small groups.

The following discussion is based on the assumptions that politics essentially involves communication phenomena and that communication in decision-making is fundamentally concerned with reducing uncertainty on the part of the decision-makers (Dyson et al., 1972; Davis, 1974a, Deutsch, 1966; Milbrath, 1963). Using this general framework, which is further explained below, it is possible to link conceptually decisional processes and outcomes. One main argument is that the way in which decisional groups go about reducing uncertainty determines, in part, the propensity of groups for policy shifts.

\section{SEARCH BEHAVIOR AND INFORMATION PROCESSING}

Social-psychological concepts which serve as potential alternatives for more traditional (as well as behavioral) nonprocess approaches in political science and rational calculus interpretations in economics are not highly developed in a decision context. However, there is a general body of theory which establishes a foundation for social-psychological integration-cognitive process approaches. It is a broad field which reflects concern for how information is processed, the search for alternatives, the organization of cognitive components, perception of others, and the definition of the situation within which decision-making occurs. Although its utility and origins have been traced elsewhere (Holsti, 1976; Kirkpatrick, 1975c), its cognitive and perceptual emphasis is most noted in the fields of organizational behavior and foreign policy decision-making. It is indebted to the early work of Herbert Simon and his "Carnegie School," which placed a unique emphasis on information processing and constraints on rational choice-knowledge of consequences was seen as fragmentary and incomplete, perception of alternatives as limited, and values at tached to consequences in the future as only imperfectly anticipated (Simon, 1957: 81-83; 1958; also see Storing, 1962). In work with March (1958), Simon offered a critique of the traditional administrative science approach by emphasizing the incomplete and inaccurate motivational assumptions (e.g., monetary reward) underlying previous theory, and the importance of constraints and cognition in the search process-"a theory of choice without a theory of search is inadequate" (March and Simon, 1958: 174). 
In summary, the information-processing school emphasizes the importance of previous information, the complexity and volume of new information, the role of existing belief systems, levels of cognitive complexity, the search process, selective responsiveness, and perceptual distortion. Most research utilizing these concepts in political science, however, has been limited to work on mass publics, especially public participation and electoral behavior. Indeed, its research utility has been confined to forms of inquiry which pay scant attention to the process of decision-making, to institutional settings, or to small groups. The following framework emphasizes search behavior and information processing with roots in this tradition.

Decision-making is generally characterized by choice behavior. As such, it is necessarily information-dependent. Because decision-makers cannot know everything relevant to deciding, it is necessary for them to seek information in order to reduce as much uncertainty as possible and thereby minimize the possibilities for error. Alternatively, certain conditions may lead to the avoidance of information or to a selective search in order to reduce cognitive tension or reinforce existing beliefs. Decisionmakers need information on the nature of the problem being considered, the problem environment, the nature and consequences of alternative actions, and feedback from previous decisions on the problem or related problems (Skjei, 1973). The quality of decisions largely hinges on the ability of decision-makers to obtain and process this information. Additionally, given the fact that political decision-making generally involves open solution sets (i.e., does not involve the discovery of a single correct analogarithm), decision-makers need information from one another concerning the possible bases for bargaining, negotiation, and compromise (Dyson et al., 1972; Kelley and Thibaut, 1968). Therefore, in a fundamental sense, most decision-related behavior prior to the decision itself involves attempts by decision-makers to remove uncertainty through communication with each other and with actors outside the decisional group. This contention is hardly novel, yet discussions of information search behavior by decision-makers comprises a rather small portion of the decision-making literature.

\section{Constraints on Uncertainty Reduction in Decision-Making}

The search for information in order to solve a problem or research a decision is not costless. As Downs (1967: 3) observes: 
Information is costly because it takes time, effort, and sometimes money to obtain data and comprehend their meaning. Decision-makers have only limited capabilities regarding the amount of time they can spend making decisions, the number of issues they can consider simultaneously, and the amount of data they can absorb regarding any one problem.

Consequently, it is impossible for any decision-making group to remove all uncertainty surrounding any particular decision. This assertion raises the theoretical issue of specifying the relationships between particular types of constraints on decision-makers, including psychological ones, and the kinds and amount of information sought or avoided during decisional processes.

Information constraints. One set of constraints on decision-makers is, as Downs suggests, the cost of obtaining information. Theorists approaching the problem from this perspective have generally taken the position that decision-makers utilize some sort of cost-benefit criteria during the information search phase (Downs, 1967; Skjei, 1973). The view is that decision-makers cease acquiring information when the cost of acquiring an additional unit of information exceeds the benefits to be gained by the reduction of uncertainty associated with the unit of information. Such an "economy of information theory," however, is severely limited as a descriptive theory of information search in decision-making. Like other theories of behavior based on the assumption of individual rationality, information economy theory rests on some very problematical premises (Conrad, 1970). Moreover, when applied to decision-making groups, these problems are compounded-given the fact that political decisions are seldom made by individuals in isolation but rather in the context of internal organizational groups and external (constituents, clienteles) reference groups. As Olson (1971: 22-36) has demonstrated, groups usually cannot obtain optimal levels of any collective good unless all members of the group place equal value on the good in question. Accordingly, because there is no reason to assume that members of any particular decision-making group will place the same value on the acquisition of information, it is doubtful that the group will acquire an optimal level of information. Nevertheless, cost is a very real constraint on decision-makers' ability to remove uncertainty. This includes not only time and other resources, but also sunk costs or psychological commitments to previous information and policy (Wilensky, 1967: 78). 
Organizational constraints. Organizational routines also impose limitations on the search for information. First suggested by Simon (1957), this view holds that standard organizational procedures and communication patterns largely predetermine the type and quantity of information acquired by decision-makers. Cyert and March (1963) offer ample evidence for this contention in their case studies of industrial decisionmakers. Allison (1971) also demonstrates the viability of this model of information search in his analysis of the Cuban missile crisis. Apparently, standard administrative procedures serve a significant channeling function with respect to organizational decision-making (Feldman and Kanter, 1965).

Situational constraints. Situations also condition search behavior. Hermann (1969), for example, suggests that consideration of alternatives is constrained in crisis decision-making (see Holsti and George, 1975). Presumably, decision-makers are more easily overloaded (i.e., reach information-processing capacity) in crisis situations than in noncrisis situations and, consequently, tend to limit search activity during stress. This contention is supported by a large volume of social-psychological research on stress (Janis, 1971). The more general conceptualization of Snyder and his associates (1962) posits that search behavior in decisionmaking is determined by the initial definition of the situation by decision-makers. Unfortunately, their framework is so complex that it has been severely criticized as a useful model (McCloskey, 1956; Rosenau, 1967). Others, however, have used the definition of the situation notion to good advantage in frameworks which are less global and awkward (Pruitt, 1965).

Motive constraints. It is likely that search behavior is partially guided by motives or affective needs of the decision-maker, in much the same way as theorists link opinion formation and change to the functional requisites of the individual (Smith et al., 1956; Katz, 1960; Lane, 1959; see discussion by Kirkpatrick and Pettit, 1972: 267-270). The comprehensiveness, complexity, and selectivity of information search behavior may be dependent upon individual functional needs, such as object appraisal (understanding and controlling events), social adjustment (affiliative needs), or ego defense (the projection of intrapsychic tension). Similarly, Nimmo (1974) suggests that types of political imagery will reflect expressive, evaluative, and instrumental goals or motives (also see Wilker 
and Milbrath, 1970). In decision-specific terms, for example, Katz and Kahn (1966) suggest that decision-makers project their own internal feelings onto others and perceive that others' attitudes are congruent, thereby reducing the need to collect new information. In general, there is a relationship between the type of needs fulfilled by holding certain beliefs and the type of influence that information and significant others have on the decision-maker, e.g., existing beliefs that perform an object appraisal function are likely to be influenced by new information, whereas those based on social adjustment needs are more likely to be influenced by reference group identifications (Smith, 1968; Schoettle, 1968).

A more extensive literature on personality attributes is firmly rooted in need, motivation, and function concepts (see Kirkpatrick and Pettit, 1972). Several components of this research tradition bear on the alternative choice process: (1) Motives are states of tension caused by unsatisfied needs which trigger decision-making behavior (Argyris, 1957; Brim et al., 1962; Scott, 1967; Hersey and Blanchard, 1967). (2) Low self-esteem, psychic deprivation, inflexibility, and over-conformity are associated with inhibited information seeking in the context of allaying anxiety and supporting needs (Knutson, 1972). (3) Dogmatic and authoritarian personalities may obstruct decisions, limit the impact of new information, lead to decisions which merely justify existing beliefs, and demand subservience that makes it risky for others to offer negative or unpleasant information about alternatives (Bensman and Rosenberg, 1960; also see Lasswell, 1954; Kirscht and Dillehay, 1967). (4) After one progresses up the need hierarchy (when basic needs are met) to higher-order needs (e.g., self-actualization), we can begin to speak of decision-making flexibility, competent problem-solving, tolerance, and the realistic assessment of alternatives (Argyris, 1957; Knutson, 1972). (5) High levels of ego involvement are associated with goal-setting behavior (Sherif and Cantril, 1947), task performance and high levels of aspiration (Ferguson, 1962), and fewer categories for classifying statements of alternatives (LaFave and Sherif, 1968). (6) Flexibility in the adjustment of levels of aspiration bears directly on the search process and is influenced by the availability of bland alternatives (March and Simon, 1958; Siegel, 1957: Siegel and Fouraker, 1960).

While the personality theory school in both political science and psychology is massive and complex, we have chosen to focus on a selected subset of attribute and motive qualities which may bear directly on the 
search process (for reviews, see Kirkpatrick, 1975c: 76-79; Kirkpatrick and Pettit, 1972: 16-72).

Cognitive constraints. In addition to motives or functional needs, there is a variety of cognitive limitations imposed on the uncertainty and tension reduction process. While informational, organizational, and situational constraints tend to emphasize environmentally determined influences, affective and cognitive limitations originate from the decision-maker. Indeed, the prevailing view of "intended rationality" which often underlies the Carnegie School gives conceptual priority to environmental or stimulus-determined forces, whereas affective and cognitive limitations may be viewed as individual or perceiver-determined (for a review of these alternative conceptualizations in the study of political perception, see Kirkpatrick and Pettit, 1972: 199-267; also see Sigel, 1964; Nimmo and Savage, 1971). A point of general agreement among cognitive psychologists is that all acts of cognition are essentially constructive in nature. That is, we create perceptions of our environment rather than directly reflecting stimuli as a mirror reflects a physical image: "seeing, hearing, and remembering are all acts of construction, which may make more or less use of stimulus information depending on the circumstances" (Neisser, 1966: $10)$.

Because decision-makers can only attend to a limited amount of information, they necessarily utilize a variety of conceptual rules to simplify decisional parameters. Newell et al. (1958) refer to these "rules of thumb" as heuristics. A common type of heuristic is analogy. Using analogy, decision-makers look for similarities between the problem they wish to solve and other problems they have solved in the past. Wildavsky (1964) and Fenno (1966) have both observed the frequent reliance on heuristics in congressional committee decision-making. Additionally, the work of Wildavsky (1964: 47-55) at the national government level and Schick (1971: 164-191) at the state governmental level suggests that different simplifying rules are associated with different roles in the budgetary process. For example, legislative committees concerned with authorization measures appear to search for different information from executive agencies than committees concerned with appropriation decisions.

Research by Schroeder et al. (1967), Shapiro and Bonham (1973), and Bieri (1955) indicates that the conceptual complexity of decision-makers' cognitive structures also influences information search. The experimental 
and simulation studies of these investigators indicate that decision-making groups composed of cognitively complex decision-makers have a greater ability to process information than groups composed of members with moderate to low levels of cognitive complexity. Similarly, complex cognitive structures are associated with heightened search activity (Nidorf and Crockett, 1964) and less dependence on social influence (Bieri, 1955). Continued efforts along the lines suggested by these research efforts appear to promise considerable insight into the process/outcome problem in decision-making theory and research.

In addition to cognitive complexity, dissonance theory suggests that conflict between alternatives and/or significant others creates tension to reduce it through a variety of mechanisms which are relevant to the search process. These include nondecision or avoidance of alternatives which increase tension, changes in existing cognition, or the development of new cognitions, information, or alternatives (Festinger, 1964). The latter effect is especially dependent upon the nature and credibility of information sources, and it is likely to be the stage which produces divergence in the attractiveness of alternatives through the search for supportive information or the avoidance of discrepant information (for a discussion of predecisional stress, see Holsti and George, 1975: 264).

Group constraints. Finally, a variety of variables associated with decision-making groups themselves appear to constrain the ability of decision-makers to reduce uncertainty, thereby affecting the search process. Decision-making in a group context involves more than the sum of individual judgments-it leads to changes in problem solutions affected by social influence, conformity, and feelings of community. The group context and its underlying processes affect (1) the speed and accuracy of responses to stimuli, perceptual processes, information dependence, and the cognitive processes of conceptualizing, relating, and reasoning (see Thibaut and Kelley, 1959; Zajonc, 1965); (2) receptivity of information and the multiplicity of alternatives examined (see Kelley and Thibaut, 1968); and (3) the number and creativity of alternatives (Osborn, 1957).

Group cohesion and conformity tendencies appear to be important in this regard. A prominent political study in this vein is Janis' (1972) study of several foreign policy "fiascos." Janis theorizes that cohesion and conformity tendencies present in all small group situations tend to result in what he terms "groupthink," which involves limited search behavior by decision-makers and a concomitant inability or failure to correct initial estimate errors. Janis' conclusions about the foreign policy fiascos he 
studied are based on historical anecdotal evidence, but the general proposition that group processes may inhibit accurate assessment of decisional issues is buttressed by an extensive collection of experimental evidence from laboratory studies of group problem solving processes (Cartwright, 1968).

The nature of group leadership also has important implications for the uncertainty reduction behavior of groups. Numerous field and laboratory studies have demonstrated that leader characteristics and leadership style are major determinants of group task performance (Stogdill, 1974: 363-407). Given the fact that task performance partly hinges on the accurate assessment of task requirements and resources, it logically follows that leaders influence the search for information (Maier and Solem, 1952; Osborn, 1957; Taylor et al. 1958). Support for this argument is implied by Janis' work cited above. Common to all the foreign policy decisions studied by Janis, was the presence of a single definite group leader, usually the head of state. It may be that the limited search behavior of these groups was partially the result of single-leader dominance. Additional evidence for this hypothesis is provided by the the observance of committee chairman dominance over committee deliberations in congressional settings (Fenno, 1966).

In addition, the search for information in groups is partly determined by the level of consensus in groups. If group members are in total accord with respect to decisional issues, then there is little need to seek information for purposes of bargaining and negotiation. Alternatively, if group members are in disagreement over preferences and/or instrumentalities, then they need to acquire information in order to resolve these differences (Kelley and Thibaut, 1968). This is clearly not an exhaustive list of group characteristic variables, but those mentioned illustrate the potential group influences on uncertainty reduction by decision-making groups.

In summary, decision-makers need information in order to reach a decision, but their ability to obtain and process enough information to reduce uncertainty is constrained by the costs associated with obtaining information, their cognitive capacities and functional needs, situational and organizational conditions, and by a variety of group-specific characteristics. In order to link decisional processes and outcomes, it is therefore necessary to determine the linkages between these constraints, the types and amounts of information sought by groups, and final decisional outcomes. 


\section{Information Types}

An initial step in investigating information search behavior requires the establishment of a taxonomy of information (see Jeffers et al., 1976), as some kinds of information are more important at various stages of decision-making than others and some kinds are more readily available to decision-makers (i.e., their ability to obtain it is less constrained). One useful typology is provided by Skjei (1973: 9-46), who suggests that there are four types of relevant decision information: (1) problem information; (2) problem environment information; (3) alternatives information; and (4) feedback information. Problem information concerns the development of basic objectives, analysis of needs, and the development of decisional standards; it therefore involves a programmatic focus. Problem environment information relates to the various factors over which decision-makers have little or no control, but which will influence the implementation of their decision. Included among such factors are basic resources, population characteristics and trends, and legal constraints. Alternatives information involves various means-ends analysis; or the development of alternatives and comparisons of the benefits and costs associated with each alternative. Feedback information refers to the review of past decisions on the problem or related problems.

Furthermore, we may conceptualize information search across substantive types in three general ways. First, level of information can be defined in terms of the sheer volume of information sought, regardless of content. Second, it is differentiated by the diversity of types, or the extent to which various types of information are gathered by decision-makers. Finally, level of search may be described in terms of the diversity within types, or the extent to which different information content within the general types is sought.

A final distinction between information types concerns the difference between internally and externally generated information. In any given decision-making group, individuals will have varying degrees of information about any particular problem under consideration. This may be due to differential experience with the problem or varying ability to integrate problem information with past experience or stored information. In either case, we may assume that some decisions, as well as individual characteristics, require that decision-makers rely more heavily on external information than internal information or vice versa. In studying information search behavior, therefore, we must be aware of both internally and externally oriented search. 


\section{Political Science Research on the Search Process}

Given the importance of information search in decision-making, it is curious that few political scientists have specifically addressed it in their research. In a recent effort to assess our knowledge of the search process, Davis (1974a) was able to catalog only a few nonhistorical empirical treatments. A sociologist, Harold Wilensky, reached a similar conclusion in his investigation of the generation and use of "intelligence" in governmental and nongovernmental organizations: "It is strange that social scientists, who are by profession devoted to the application of reason to man's affairs, have been more impressed by the use and misuse of power than by the use and misuse of knowledge" (Wilensky, 1967: 7). Unfortunately, Wilensky's own investigation does not fill the substantial theoretical gap in decision-making research. His arguments refer to organizations generally, rather than to decision-making groups; his data are historical/anecdotal; and, therefore, his generalizations are necessarily limited. Similarly, the foreign policy decision-making literature which raises questions of the search process (see Holsti, 1976), is also limited by theoretical focus and data sources. The work of Fenno (1966), Wildavsky (1964), and Huitt (1957) is also suggestive with respect to the search process in congressional committees, but again search is not a major focus for them, their conceptualization is very general, and their data are anecdotal. Janis (1972) and Allison (1971) probably come closest to specifically addressing the search for alternatives by decision-makers. Janis, however, is rather vague with regard to search and Allison's work, though very explicit conceptually, is a case study. Furthermore, both Janis and Allison address peculiar types of decisions, i.e., foreign policy decisions under crisis conditions.

A recent study by Skjei (1973) specifically addresses the question of information generation for political decision-making. His focus, however, is the impact of various kinds of information presented to decision-makers on final choices. Skjei raises the issue of the nature of information necessary to "control" decision-making in terms of collective payoff for society. This systemic approach to search processes and the fact that he tests propositions with case study data concerning the decentralization of New York City schools, limit the usefulness of the study as a guide to small decision-making groups. Skjei is singular, however, in his endeavors to treat theoretically types of decision-relevant information and in his speculation concerning the nature of groups external to decision-makers which are likely to generate these various kinds of information. 
There have been a few experimental and simulation investigations of decision-making in which search has been a major dependent variable. In Hermann's simulation of foreign policy decision-making by small groups under crisis conditions, the author found moderate support for the hypothesis that search for alternatives is more constrained under crisis conditions than noncrisis situations (Hermann, 1969: ch. 7). In their simulation of the Jordanian crisis of 1970, Shapiro and Bonham (1973) found that search for decisional information increased as the cognitive complexity of decision-makers increased. This finding is specific to individuals rather than to groups. In an experimental investigation of budgetary decision-making, Davis $(1974 a ; 1974 b ; 1976)$ confirmed the findings of Shapiro and Bonham with respect to internal search within decision-making groups (i.e., the exchange of information between group members of purposes of reducing uncertainty). In the Davis study, cognitive complexity of decision-makers did not appear to affect the degree of external search for information (i.e., request for information from sources outside the group). Davis also found that internal information search became more constrained in groups with single dominant leaders as the time for decision narrowed. Although he did not engage in hypothesis-testing with respect to search processes in decision-making groups, Barber's (1966) laboratory study of Boards of Finance in Connecticut illustrates the use of a variety of heuristic or simplifying rules in budgetary decision-making. Barber's detailed observations indicated that such groups utilize several criteria for simplification in budgeting: controllability, size and increase, concreteness, immediacy, uncertainty, and dollars and costs (pp. 33-47).

In summary, the need for systematic hypothesis-testing concerning search processes in political decision-making is apparent. Political scientists have tended to avoid the problem and existing research is mostly descriptive. Developing political decision-making theory and closing the process/outcome gap in existing theory will require greater effort to test theoretically derived propositions in a way which allows for generalizations beyond rather narrow cases.

\section{CHOICE SHIFTS AND GROUP DECISION-MAKING}

A major component of the decision-making process in addition to search behavior is the process of arriving at final choices following alternative enumeration and the assessment of consequences. Since a 
considerable portion of political decision-making occurs in small groups, a necessary function of any decision theory is to explain the effects of group processes on the outcome-the decision itself. How does a set of individual beliefs become transformed into a group decision, and how does that decisional result differ from the original beliefs of the participants? There is a substantial body of social-psychological theory which addresses this individual-group transformation, the changes and shifts relevant to final outcomes, and the various individual and group characteristics which influence the process.

\section{The Risky Shift}

One major category of social-psychological research addresses the "risky shift" hypothesis (for a review, see Kirkpatrick, 1975b; 1975c). Conventional political wisdom supports a rather slow and conservative decision process in groups; Whyte's (1956) “organization man," Presthus' (1962) "indifferent," Peter's (Hull and Peter, 1969) "principle," and Kaufman's (1973) "decidophobia" pervade even the most popular literature on groups, decisions, and contemporary society. Yet "risky shift" research has found that group decisions are more risky than individual decisions. This conflict between two general schools of theory and research exemplifies the need for more systematic attention to the subject.

The central question of the "risky shift" literature has inquired as to whether groups make riskier decisions than individuals. In the only comprehensive book on the subject, Kogan and Wallach (1964: 1) justify the use of the risk hypothesis for decision-making:

Decision-making... involves the weighing of alternatives in terms of their desirabilities and their likelihoods... issues concerning the avoidance or acceptance of risks in arriving at decisions hence are likely to be important ingredients in thinking processes.

In order to evaluate properly the "risky shift" hypothesis, a brief review of the methods and models employed to explain the hypothesis is necessary. Finally, the evolution of the risk conceptualization to a more general choice-shift formulation, and its applicability to political decision-making analysis is outlined.

Most research on the risky shift evolved from a single "Choice Dilemma Questionnaire" (CDQ), first constructed by Kogan and Wallach in 1959 to 
measure sex differences (Wallach and Kogan, 1959: 554-564) and subsequently applied to risk-taking behavior in groups by Stoner (1961). The CDQ is a series of hypothetical life situations where the subjects are asked to advise the decision-maker in each situation. Each item is built in such a manner that one alternative is a risky choice with a potential for failure, while the other choice is a cautious one urging the individual to remain in his/her present life situation (for a complete list of the CDQ items, see Kogan and Wallach, 1964: Appendix E). The shift has most commonly been referred to as the "risky shift" phenomenon because of the tendency to shift in the risky direction in the group context. Explanations have centered on group influences for increased riskiness and are typically drawn from one of four major categories of explanation: statistical, cognitive, interactive, and affective models (Vinokur, 1971b; generally, see Brown, 1965; Kelley and Thibaut, 1968; Dion et al. 1970; Journal of Personality and Social Psychology 3, 1971-entire issue).

Statistical models. The statistical model explains the risky shift in terms of the decisional rules used in the group context. Less theoretically satisfying than other models, the explained shift is analyzed only in terms of consensus versus majority decision rules (see Zajonc et al., 1972).

Cognitive models. Two forms of explanation are often evident in the cognitive model. First, the "information relevant to the task" hypothesis postulates that group discussion adds new information (content) beyond any interactive component (Kogan and Wallach, 1967; Pruitt and Teger, 1969; Vinokur, 1971 a). The other major cognitive explanation is based on decision principles rooted in rational choice models (see Lee, 1971): the subjective expected utility model is a predictor for risk-level preferences, i.e., individuals do not feel more risky, but change because the value of success is altered in group discussion, thereby making the shift rational (Burnstein, et al., 1971; Cartwright, 1971; Vinokur, 1971 a).

Interactive models. These models are based more on sociological than psychological explanations, claiming that shifts are due to interactions within the group as they relate to problem-solving and the emergence of leaders. Leadership theory, first purposed by Marquis (1962), hypothesizes that high risk-takers are more persuasive in group discussion (see also Wallach, Kogan, and Bem, 1962). One author suggests two subtheories of leadership: leader confidence theory-Ss who are initially higher risk-takers 
are more confident, thus more influential; and "rhetoric of risk" theory-risky language is more dramatic and persuasive (Pruitt, 1971a). The other interactive hypothesis is based on group problem-solving. This analogy holds that groups are better at solving problems than individuals (Faust, 1959), and that group discussion is a vital element in the shift (Rettig, 1966). Nevertheless, the interactive interpretation is not universally accepted, given indications that shifts may occur without group discussion (see Pruitt, 1971 b).

Affective models. Most research on the risky shift phenomenon falls within a category of affective models treating the effects that groups have on individuals in the presence of others.

Diffusion-of-responsibility theory was the earliest of these explanations for risk. The group decision reduces the subject's anxiety about risk and the possible negative consequences, thereby alleviating individual responsibility for the decision and facilitating risky shifts (Kogan and Wallach, 1967). The emotional bonds encountered in a group situation are relevant to this hypothesis; if those bonds are strong, a risky shift is likely to occur (Teger and Pruitt, 1967).

Familiarization theory hypothesizes that group discussion is only a method for the individual to become more acquainted with the information, thus lowering uncertainty and increasing risk (Bateson, 1966; Flanders and Thistlethwaite, 1967). This interpretation has been contradicted by research findings and has been increasingly subject to scholarly at tack (Teger et al., 1970; Dion and Miller, 1971; Castore, 1972).

Value theory is the most general and widely supported of the various theories of risk-taking behavior. Over the last ten years, value theory has generally been confirmed as an explanation of the risky shift phenomenon, and various subtheories have developed from the model. Roger Brown (1965) first proposed the risk-as-value theory by showing that when risk was the valued or admired choice, the subject generally saw himself as more risky than others around him. When the individual moves in to the group environment, he finds others riskier than he, and thus shifts further out on the risky dimension.

The strength of value theory is that it can account for cautious shifts as well as risky ones, whereas the other affective theories can only account for the risky shift. In value theory, if the cautious response is the more valued one, the shift in the group context will move in that direction.

Stoner (1968) constructed a three-part hypothesis that has been generally used in testing value theory. First, individuals make their own 
decision in a manner consistent with widely held values. Second, individuals consider themselves more consistent (not necessarily risky) with those values than others similar to themselves. Third, when group discussion and decision-making shows the individual that others are more consistent with those values than the individual's own previous decision, the subject will shift in the valued direction. If one valued a direction different from the group shift, one would tend to resist such movement.

Although slightly different methodologies have been used in testing value theory, the major studies have confirmed these basic hypotheses (Lamm, Trommsdorff, and Kogan, 1970; Clark et al., 1971; Lamm, Schaude, and Trommsdorff, 1971; Ferguson and Vidmar, 1971; Baron et al., 1973). Additionally, Levinger and Schneider (1969) have examined only pretest responses, while Jellison and Riskind (1970) were concerned with the abilities of individuals and their level of risk. Even studies at tempting to test other affective hypotheses have found more evidence for value theory (Teger and Pruitt, 1967; Wallach et al., 1968).

\section{The Emerging Relevance of Choice Shift Concepts}

The risky shift phenomenon has generated over 300 research products since the original work by Stoner (Myers, 1973). Yet the general reliance on a single CDQ questionnaire has created a sense of overkill; indeed, the basic concept of a CDQ is questionable. The subject in an experiment is offering a willingness to take risks in a purely hypothetical situation. Political decisions are not based solely on the riskiness of the decisionmaker, but often the perceived impact on the population being affected. The risky shift measured in this way is only one element of choice-shift behavior and of group effects on individuals (Walker, 1975).

Levinger and Schneider (1969) were the first to recognize that "choice shift" was a more relevant conceptualization than "risky shift." Yet their references were limited to the possibilities of cautious, as well as risky, shifts. Moscovici and Zavalloni (1969) broadened the conceptualization of choice shifts into attitude shifts on French students, and Myers and Bishop (1970) used a similar method on race relations attitudes among American students. In order to explain political choice shifts, such operationalizations are preferred over the CDQ-life situation items. Except for value theory, however, all previous theories are limited to explanations of risk; yet the other models may be redefined to test general choice shifts. 
The statistical model's treatment of decision rules, for example, has been applied experimentally on political policy attitudinal items. The findings suggest greater shifts among majority rule groups over consensus rule groups (Kirkpatrick and Robertson, 1976). The diffusion-of-responsibility model suggests that anxiety reduction through group identification or cohesiveness is the prime element in group shift. Other models, such as those emphasizing leader confidence, based on sociological interaction may be analyzed through various sociometric tests useful in measuring interpersonal influence (Kerlinger, 1973). Since value theory is applicable to general choice shifts as well as the risky shift, little redefinition is necessary. However, the use of Likert-type items, applied first by Moscovici and Zavalloni (1969), conforms more closely to a general choice shift mode than does more traditional CDQ measurement. Further examination of a more general polarization hypothesis has been suggested recently by findings that the group decision is more extreme or polarized than the mean of individual pretest positions (for a review see, Myers and Lamm, forthcoming). Since most of the models are interrelated, experimental treatments should begin to broaden their scope to include interactive elements between the models-a general failure of previous research efforts. Without such theoretical linkages, development of political choice shift explanations will be excessively fragmentary.

\section{Political Science Research on Choice Shifts}

Although small groups play a major role in political decision-making, political science has largely ignored the effects of the group prucess on choice shifts. Nonexperimental research has been generally oriented toward either historical analysis or collegial court behavior. Historical analyses, rich in process behavior, are necessarily confined to ex post facto models and have little predictive ability. An oft-cited example is Janis' Victims of Groupthink (1972), which suggests that group decisions in foreign policy are often defective. In collegial court behavior, two researchers have found that judges will shift to a more libertarian position and are more likely to exercise judicial review while members of a group (Walker and Main, 1973; Main and Walker, 1973). Other studies have hinted at the effects of group behavior and the impact of identification with groups on individual behavior (McWhirter, 1974; Raven, 1974).

Experimental applications of the choice shift in political science are even more rare (see reviews by Kirkpatrick, 1975b, and Walker, 1975). In 
an attempt to revise the traditional CDQ to make it more applicable to political decisions, Kirkpatrick et al. (1975) created new political CDQ items and tested the effects of information and discussion on experimental groups. Their findings emphasize the cautious shift as the prime change in political group settings.

While the choice dilemma technique has dominated social-psychological research on the choice shift, it has no proprietary rights to theory. Successful substitute measures have appeared throughout the research literature (e.g., substituting attitude scales-Moscovici and Zavalloni, 1969). Using such cues, Kirkpatrick and Robertson (1976) have created non-CDQ items more directly relevant to policy issues. In a test of value theory, the findings suggest that groups shift to more extreme or firm positions when Ss recognize that others are not more neutral than themselves.

\section{ALTERNATIVE SEARCH AND CHOICE SHIFT LINKAGES}

The two fundamental decision processes of searching for aiternatives and shifting choices on the basis of group effects are complementary to one another, yet there is no research which attempts to link these processes. The strength of the choice shift paradigm is its focus on changes in outcomes as a result of group effects influencing levels of certainty about decisional consequences. The risky shift concept, for example, led to findings emphasizing greater uncertainty in terms of decisional consequences in group situations compared to individual choice; and, similarly, the shift to caution involves greater certainty in terms of decisional consequences in groups versus the individual. Choice shifts therefore focus on the consequences of alternatives, yet the paradigm has little to offer in terms of the search for alternatives. Indeed, the classic experimental model of choice shifts includes the presentation of a single alternative (and, implicitly, its obverse), along which individuals and groups vary by levels of probability assigned to the certainty of outcomes.

On the other hand, the search literature tends to avoid a focus on consequences and instead relies on concepts and constraints associated with informational/alternative uncertainty reduction. Knowledge of alternative search behavior does not necessarily provide us with knowledge of choice shifts associated with the various consequences of alternatives, even though both processes may be dependent upon similar sets of individual 
and group effects. Informational variables, for example, play an important role in the rather disparate theorizing about search behavior and choice shift; however, the effects of such variables have never been examined simultaneously. Similarly, other individual factors such as cognitive complexity and motivational needs, as well as group effects such as conformity and leadership, are relevant to both processes. While these two processes are not mutually exclusive-indeed, some extreme alternatives may have more or less agreed-upon consequences (i.e., they converge)-

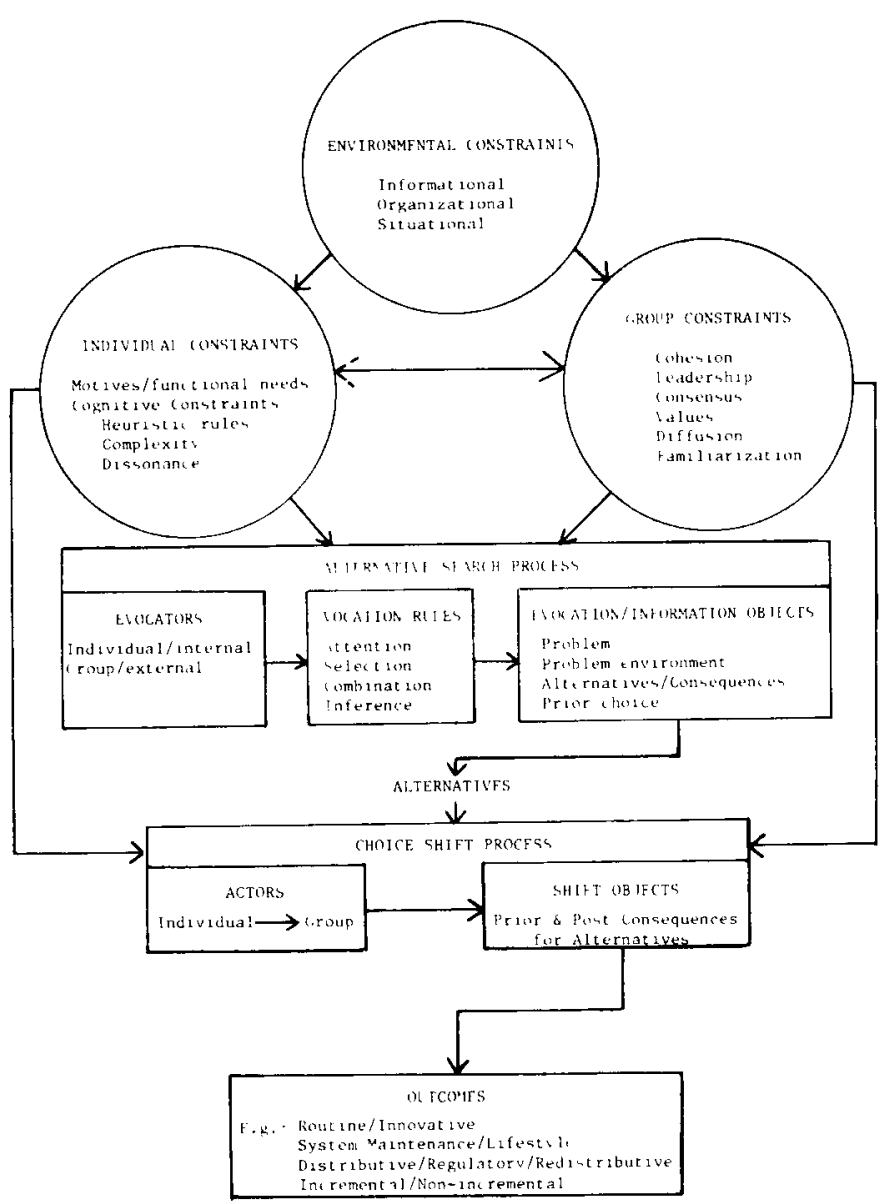

Figure 1: A Framework for Political Decision-Making 
conceptual distinctions between them should facilitate linkages and enable us to focus on both in the decision process. Either one viewed alone is insufficient; even a rational-comprehensive search is theoretically irrelevant if it cannot be linked to outcomes; and choice shifts, regardless of their direction, have too often been isolated from a variety of available alternatives. The rational search perspective has too often assumed that consequences are known and that probabilities are agreed upon. In sum, both processes involve important constraints on more rational models, and the establishment of empirical linkages between the two is crucial if we are to understand decision-making.

\section{SUMMARY THEORETICAL FRAMEWORK}

The preceding theory and research offers cues to hypothesis-testing and operationalization; most important, it suggests a framework for analyzing political decisions applied to a variety of settings. This summary framework, presented in Figure 1, is offered as a simplifying device and as a translation mechanism to encourage movement from general bodies of theory to specific operationalizations. While its categories are not always mutually exclusive, and while it does not address a host of subtle and highly complex effects discussed above, it treats the primary components utilized in this investigation. Furthermore, the arrows depicting linkages within and between search and shift processes should not detract from the iterative nature of those processes.

The framework begins at the broadest level with a concern for environmental factors. While political culture and the sociopolitical milieu obviously form a backdrop for political decision-making, the environmental component specifically addresses several constraints on decisionmaking. These include (1) information-especially that about alternatives and consequences-which varies in level of complexity, volume, spontaneity, source credibility, and costs for obtaining it; (2) organizational characteristics, procedures, majority/consensus decision rules, and accepted modes for channeling information, including that from external groups; and (3) situational constraints which vary across time and policy arenas and which are characterized by varying levels of external group, clientele, and constituency involvement.

These process-relevant environmental factors are mediated by both individual and group constraints which are, in turn, mutually dependent. Those factors which are primarily individual in origin or perceiver-deter- 
mined include the motives or functional needs of decision-makers and their cognitive characteristics. The latter include a variety of heuristic rules employed, the level of cognitive complexity, and the extent of predecisional dissonance. These individual factors are tempered by a variety of group constraints, including prevailing group values, levels of consensus, diffusion and familiarization processes, interpersonal ties and group cohesion, and leadership patterns. Both individual and group factors filter environmental constraints and bear directly on the search process and, either directly or indirectly, influence the processes of choice shift. Although some individual and group constraints may be more relevant for the search process than for the shift process, each set of elements requires operationalization, empirical testing, and comparative examination for effects.

In addition, while the search process provides outputs in the form of alternatives (or nonalternatives) which become focal points for the perception/evaluation of consequences during potential shift processes, the nature of choice shifts will also directly reflect individual and group factors. Under conditions where search is weak or practically nonexistent, such antecedent factors may assume a primary role at the shift stage. Likewise, there may be conditions where search is complex, comprehensive, and characterized by multiple outputs, but where little consequence activity or individual-group change occurs. And as we suggested earlier, the search and shift effects may converge so as to be nearly indistinguishable in certain circumstances.

The search process itself includes various "actors" who apply various "rules" to information "objects." These actors may evoke information internally and on an individual basis, or externally on a group or significant-other basis, and they do so through a variety of "evocation rules" for attending, selecting, combining, and inferring information (Warr and Knapper, 1968) about "evocation objects." These evocation or information objects include the general .problem (definition, goals, agenda-setting), the problem environment, alternatives and consequences, and prior choices brought to attention through feedback mechanisms. Alternatives which vary in their content, volume, and complexity then result from various environmental, individual, and group constraints influencing evocators applying evocation rules to evocation objects.

The shift process involves actors who develop orientations to prior and subsequent consequences for the range of alternatives provided by the search process. These actors exhibit varying degrees and directions of 
movement from an individual to group decision. The shifts may be dependent upon various types of alternatives provided by the search process, as well as a range of individual and group constraints. The final group choice, as partially determined by decision rules filtered by other antecedent factors, constitutes an outcome. These outcomes have policy relevance (or may be policy) for any unit of analysis under examination (e.g., boards and councils) and for the level of the political system at which they occur. Their content may fall within several policy dimensions-e.g., routine or innovative policy, system maintenance, or lifestyle values (Williams, 1961; Kirkpatrick and Morgan, 1971), or distributive, regulatory, or redistributive policies (Lowi, 1964). While there is a variety of alternative conceptualizations for policy dimensions (see Kirkpatrick, 1970), these are suggestive of policy types by content and obviously reflect situational conditions. In addition, they may be distinguished by a process typology which differentiates incremental and nonincremental decisions. Such outcome types may be associated with different search and shift processes, and several important and subtle relationships may appear as effects are examined from multivariate and experimental perspectives.

Unlike most other decisional frameworks, this model incorporates a variety of environmental, individual, and group factors in the context of social-psychological theory; it specifically addresses both the search and shift process; it attends to multivariate effects which have heretofore been unexamined for either the search or shift component; and it is specifically outcome-oriented, making further distinctions between types of decisions. Moreover, the framework components are sufficiently rooted in existing research so as to enable operationalization and empirical testing.

\section{RESEARCH AGENDA}

Given the rich, albeit disparate, theoretical and empirical efforts relevant to political decision-making, there is reason for optimism about substantive developments in future research. The theoretical discussion and schema offered above provide one way for potentially integrating decision-making research from several disciplines and for reducing the gap between process and outcome concerns. There is a possibility, however, that decision-making scholars will remain firmly entrenched in an excessively compartmentalized field of inquiry, thereby precluding the development of a cumulative theoretical and empirical research tradition. 
In this regard, we offer several suggestions for future students of decision-making.

First, while it is necessary to engage in alternative theoretical treatments of political choice, it is essential that these efforts be fundamentally integrative in nature. Moreover, the incorporation of findings from several disciplines into one's own is only a necessary, but not a sufficient, condition for theoretical integration. Rather, we should concern ourselves with synthesizing both the theoretical and empirical content of decision-making research.

Second, it is essential for students of decision-making to escape the limitations of single research modes. One should not be scientifically comfortable with findings generated in only one type of research setting (e.g., laboratory, field observations). It is remarkable that a path-breaking effort such as Barber's (1966) has been met with so little interest by the political science community. Similar types of inquiry are necessary to move beyond mere analogy between laboratory and field study findings to actual investigations of the same or similar phenomena in different research settings.

A third suggestion derives from the second-that political scientists modify what appears to be the dominant disciplinary view of research validity. Students of politics appear to be excessively concerned with external validity or generalizability of research results, and hence have given special emphasis to field studies and research involving large-scale random sampling procedures. As a consequence, experimental research remains in relative infancy in political science, including the decisionmaking field. Indeed, small group analysis in controlled laboratory settings offers some distinct advantages over other approaches (Weick, 1965; Dyson, 1975). First, it enables one to observe decision-relevant behavior which is generally not open to view in natural settings. Second, the experimental research mode forces the analyst to be explicit conceptually, a shortcoming of many decision-making frameworks (see Rosenau, 1967). Most important, experimentation is virtually unparalleled as a means for insuring internal validity and testing causal relationships in a manner which allows for considerable confidence with respect to falsifying or supporting particular theoretical propositions (Hempel, 1966: 19-22). Without establishing internal validity in decision-making research, the ability to generalize to other settings or populations is fruitless (Campbell and Stanley, 1966: 5).

Furthermore, in the physical sciences, external validity is established through replication much more often than through large-scale random 
sampling. Although the more exact sciences may indeed have less difficulty associated with wide-ranging variation in units of analysis, the principle of establishing the generalizability of observed relationships through repeated testing under slightly altered research conditions is a sound guide for the social sciences.

Finally, it seems prudent to anchor our decision-making research empirically. This rather obvious assertion reflects our reading of available theoretical frameworks. Too often, decision-making scholars have provided characterizations of decision-making which do not facilitate practical operationalization of the component concepts. Throughout our discussion, we have sought to indicate empirical source materials relevant to choice processes. If microanalytic constructs of political decision-making are to survive, they must meet the test of research.

\section{REFERENCES}

ALLISON, G. T. (1971) Essence of Decision. Boston: Little, Brown.

ARGYRIS, C. (1957) Personality and Organization. New York: Harper \& Row.

ARROW, K. (1963) Social (hoice and Individual Values (second ed.). New York: John Wiley.

BARBER, J. D. (1966) Power in Committees: An Experiment in the Governmental Process. Chicago: Rand McNally.

BARON, R. S., T. C. MONSON, and P. H. BARON (1973) "Conformity pressure as a determinant of risk taking: replication and extension." J. of Personality \& Social Psy chology 28: 405-413.

BATESON, N. (1966) "Familiarization, group discussion, and risk taking." J. of Exper. Social Psychology 2: 119-129.

BENSMAN, J. and B. ROSENBERG (1960) "The meaning of work in bureaucratic society," pp. 181-197 in M. R. Stein, A. J. Vidich, and D. M. White (eds.) Identity and Anxiety. New York: Free Press.

BIERI, J. (1955) "Analyzing stimulus information in social judgments," in S. Messick and J. Ross (eds.) Measurement in Personality and Cognition. New York: John Wiley.

BRIM, O. G., D. C. GLASS, D. E. LAVIN, and N. GOODMAN (1962) Personality and the Decision Process. Stanford, Calif.: Stanford Univ. Press.

BROWN, R. (1965) Social Psychology. New York: Free Press.

BURNSTEIN, E., H. MILLER, A. VINOKUR, S. KATZ, and J. CROWLEY (1971) "Risky shift is eminently rational." J. of Personality \& Social Psychology 20: $462-471$. 
CAMPBELL, D. T. and J. C. STANLEY (1966) Experimental and Quasi-Experimental Designs for Research. Chicago: Rand McNally.

CARTWRIGHT, D. (1971) "Risk-taking by individuals and groups: an assessment of research employing choice dilemmas." J. of Personality \& Social Psychology 20: 361-378.

-- (1968) "The nature of group cohesiveness," in D. Cartwright and A. Zander (eds.) Group Dynamics: Research and Theory (third ed.). New York: Harper \& Row.

CASTORE, C. J. (1972) "Group discussion and prediscussion: assessment of preferences in the risky shift." J. of Exper. Social Psychology 8: 161-167.

CLARK, R. D., W. H. CROCKETT, and R. L. ARCHER (1971) "Risk-as-value hypothesis: the relationship between perception of self, others, and the risky shift." J. of Personality \& Social Psychology 20: 425-429.

CONRAD, T. (1970) "Rationality and political science: a critical analysis of the consumer-choice model." Polity 3: 479-494.

CYERT, R. M. and J. G. MARCH (1963) A Behavioral Theory of the Firm. Englewood Cliffs, N.J.: Prentice-Hall.

DAVIS, D. F. (1976) "Search behavior of small decision-making groups: an information processing perspective," in R. T. Golembiewski (ed.) The Small Group in Political Science: The Last Two Decades of Development. Athens: Univ. of Georgia Press.

-- - (1974a) "Search behavior in small decision-making groups: an experimental inquiry." Ph.D. dissertation, Florida State University.

- - $(1974 b)$ "Search behavior in small decision-making groups: an information processing perspective." Presented at the annual meeting of the American Political Science Association, Chicago, August 29-September 2.

DEUTSCH, K. W. (1966) The Nerves of Government. New York: Free Press.

DION, K. L. and N. MILLER (1971) "An analysis of the familiarization explanation of the risky shift." J. of Exper. Social Psychology 7: 524-533.

DION, K. L., R. S. BARON, and N. MILLER (1970) "Why do groups make riskier decisions than individuals?" pp. 306-374 in L. Berkowitz (ed.) Advances in Experimental Social Psychology, Vol. 5. New York: Academic Press.

DOWNS, A. (1967) Inside Bureaucracy. Boston: Little, Brown.

-- (1957) An Economic Theory of Democracy. New York: Harper \& Row.

DYSON, J. W. (1975) "Political experimentation: some theoretical fragments pertinent to experimental research." Presented at the annual meeting of the American Political Science Association, San Francisco, September.

,-- P.H.B. GODWIN, and L. A. HAZLEWOOD (1972) "Political discussion and decision-making in experimental small groups." Presented at the annual meeting of the American Political Science Association, Washington, D.C., September.

FAUST, W. (1959) "Group versus individual problem-solving." J. of Abnormal \& Social Psychology 59: 68-72.

FELDMAN, J. and H. E. KANTER (1965) "Organizational decision-making," pp. 614-649 in J. G. March (ed.) Handbook of Organizations. Chicago: Rand McNally.

FENNO, R. F., Jr. (1966) The Power of the Purse: Appropriations Politics in Congress. Boston: Little, Brown. 
FERGUSON, D. A. and N. VIDMAR (1971) "Effects of group discussion on estimates of culturally appropriate risk levels." J. of Personality \& Social Psychology 20: 436-445.

FERGUSON, E. D. (1962) "Ego involvement: a critical examination of some methodological issues." J. of Abnormal Psychology 64: 407-417.

FESTINGER, L. [ed.] (1964) Conflict, Decision and Dissonance. Stanford, Calif.: Stanford Univ. Press.

ILLANDERS, J. P. and D. L. THISTLETHWAITE (1967) "Effects of familiarization and group discussion upon risk-taking." J. of Personality \& Social Psychology 5: 91-97.

HEMPEL, C. G. (1966) Philosophy of Natural Science. Englewood Cliffs, N.J.: Prentice-Hall.

HERMANN, C. F. (1969) Crises in Foreign Policy. Indianapolis: Bobbs-Merrill.

HERSEY, P. and K. BLANCHARD (1967) Management of Organizational Behavior. Englewood Cliffs, N.J.: Prentice-Hall.

HOFFERBERT, R. I. (1972) "State and community policy studies: a review of comparative input-output analyses," in J. A. Robinson (ed.) Political Science Annual, Vol. 3. Indianapolis: Bobbs-Merrill.

HOLSTI, O. R. (1976) "Cognitive process approaches to decision-making: foreign policy actors viewed psychologically." Amer. Behav. Scientist 20: 11-32.

--- and A. L. GEORGE (1975) "The effects of stress on the performance of foreign policy-makers," pp. 255-319 in C. P. Cotter (ed.) Political Science Annual, Vol. 6. Indianapolis: Bobbs-Merrill.

HUITT, R. K. (1957) "The Morse committee assignment controversy: a study in Senate norms." Amer. Pol. Sci. Rev. 51: 313-329.

HULL, R. and L. J. PETER (1969) The Peter Principle. New York: Wm. Morrow.

JANIS, I. L. (1972) Victims of Groupthink. Boston: Houghton Mifflin.

-- - (1971) Stress and Frustration. New York: Harcourt, Brace \& Jovanovich.

JEFFERS, K. C., J. W. DYSON, and D. F. DAVIS (1976) "An experimental investigation of uncertainty reduction and policy shifts by small decision-making groups." Presented at the annual meeting of the Midwest Political Science Association, Chicago, April 29-May 1.

JELLISON, J. M. and J. RISKIND (1970) "A social comparison of abilities interpretation of risk-taking behavior." J. of Personality \& Social Psychology 15: 375-390.

KATZ, D. (1960) "The functional approach to the study of attitudes." Public Opinion Q. 24: 163-176.

-- and R. L. KAHN (1966) The Social Psychology of Organizations. New York: John Wiley.

KAUFMAN, W. (1973) Without Guilt and Justice: From Decidophobia to Autonomy. New York: Peter H. Wyden.

KELLEY, H. H. and J. W. THIBAUT (1968) "Group problem-solving," pp. 1-102 in G. Lindzey and E. Aronson (eds.) Handbook of Social Psychology, Vol. 4. Reading, Mass: : Addison-Wesley.

KERLINGER, F. N. (1973) Foundations of Behavioral Research (second ed.). New York: Holt, Rinehart \& Winston. 
KIRKPATRICK, S. A. (1975a) "Epistemological perspectives on the social-psychological study of decision-making." Presented at the annual meeting of the American Political Science Association, San Francisco, September.

- - (1975b) "Problems of risk-taking in bureaucracies." Presented at the annual meeting of the International Studies Association, Washington, D.C., February.

--- (1975c) "Psychological views of decision-making," pp. 39-112 in C. P. Cotter (ed.) Political Science Annual, Vol. 6. Indianapolis: Bobbs-Merrill.

-- (1970) "Multidimensional aspects of local political systems: a conceptual approach to public policy." Western Pol. Q. 23: 808-828.

--- and D. R. MORGAN (1971) "Policy support and orientations toward metropolitan political integration among urban officials." Social Sci. Q. 52: 656-671.

KIRKPATRICK, S. A., and L. K. PETTIT [eds.] (1972) The Social Psychology of Political Life. Belmont, Calif.: Duxbury.

KIRKPATRICK, S. A. and R. D. ROBERTSON (1976) "Choice shifts in political decision-making: an experimental test of value theory." Presented at the annual meeting of the Midwest Political Science Association, April 29-May 1.

KIRKPATRICK, S. A., E. L. BERNICK, R. J. THOMPSON, and R. W. RYCROFT (1975) "Risks in political decision-making: an experimental analysis of choice shifts." Exper. Study of Politics 4: 55-92.

KIRSCHT, J. P. and R. C. DILLEHAY (1967) Dimensions of Authoritarianism: A Review of Research and Theory. Lexington: Univ. of Kentucky Press.

KNUTSON, J. N. (1972) The Human Basis of the Polity. Chicago: Aldine-A therton.

KOGAN, N. and M. A. WALLACH (1967) "Risky shift phenomena in small decision-making groups: a test of the information exchange hypothesis." $J$. of Exper. Social Psychology 3: 75-84.

(1964) Risk-Taking: A Study in Cognition and Personality. New York: Holt, Rinehart \& Winston.

LaFAVE, L. and M. SHERIF (1968) "Reference scale and placement of items with the own categories technique." J. of Social Psychology 76: 75-82.

LAMM, H., E. SCHAUDE, and G. TROMMSDORFF (1971) "Risky shifts as a function of group members' value of risk and need for approval." J. of Personality \& Social Psychology 20: 430-435.

--- G. TROMMSDORIF, and N. KOGAN (1970) "Pessimism-optimism and risk taking in individual and group contexts." J. of Personality \& Social Psychology 15: $366-374$.

LANE, R. E. (1959) Political Life. New York: Free Press.

LASSWELL, H. D. (1954) "Selective effect of personality on political participation," pp. 197-225 in R. Christie and M. Jahoda (eds.) Studies in the Scope and Method of "The Authoritarian Personality." Glencoe, Ill.: Free Press.

LEE, W. (1971) Decision Theory and Human Behavior. New York: John Wiley.

LEVINGER, G. and J. SCHNEIDER (1969) "A test of the risk is a value hypothesis." J. of Personality \& Social Psychology 11: 165-169.

LOWI, T. (1964) "American business, public policy, case studies, and political theory." World Politics 16: 677-715. 
MAIER, N.R.F. and A. R. SOLEM (1952) "The contribution of a discussion leader to the quality of group thinking: the effective use of minority opinions." Human Relations 5: 277-288.

MAIN, E. C. and T. G. WALKER (1973) "Choice shifts and extreme behavior: judicial review in the federal courts." J. of Social Psychology 91: 215-221.

MARCH, J. G. and H. A. SIMON (1958) Organizations. New York: John Wiley.

MARQUIS, D. A. (1962) "Individual responsibility and group decisions involving risk." Industrial Management Rev. 3: 8-23.

MCCLOSKY, H. (1956) "Concerning strategies for a science of international politics." World Politics 8: 281-295.

McWHIRTER, D. A. (1974) "Testing for groupthink: the effect of anticipated group membership on individual decision-making." Presented at the annual meeting of the American Political Science Association, Chicago.

MILBRATH, L. (1963) The Washingt on Lobbyists. Chicago: Rand McNally.

MOSCOVICI, S. and M. ZAVALLONI (1969) "The group as a polarizer of attitudes." J. of Personality \& Social Psychology 12: 125-135.

MYERS, D. G. (1973) "The polarizing effects of group discussion." Hope College. (mimeo)

--- and G. D. BISHOP (1970) "Discussion effects on racial attitudes." Science 169: 778-789.

MYERS, D. G. and H. LAMM (forthcoming) "The group polarization phenomenon." Psych. Bull.

NEISSER, U. (1966) Cognitive Psychology. New York: Appleton-Century-Crofts.

NEWELL, A., J. C. SHAW, and H. A. SIMON (1958) "Elements of a theory of human problem-solving." Psych. Rev. 65: 151-166.

NIDORF, L. J. and W. CROCKETT (1964) "Some factors affecting the amounts of information sought about others." J. of Abnormal \& Social Psychology 69: 98-101.

NIMMO, D. D. (1974) Popular Images of Politics. Englewood Cliffs, N.J.: Prentice-Hall.

--- and R. L. SAVAGE (1971) "Political images and political perceptions." Exper. Study of Politics 1: 1-37.

OLSON, M. (1971) The Logic of Collective Action (second ed.). New York: Schocken.

OSBORN, A. F. (1957) Applied Imagination (rev. ed.). New York: Scribner's.

PRESTHUS, R. (1962) The Organizational Society. New York: Random House.

PRUITT, D. G. (1971a) "Choice shifts in group discussion: an introductory review." J. of Personality \& Social Psychology 20: 339-360.

-- (1971b) "Conclusions: toward an understanding of choice shifts in group discussion." J. of Personality \& Social Psychology 20: 495-510.

-. (1965) "Definition of the situation as a determinant of international action," pp. 391-433 in H. C. Kelman (ed.) International Behavior: A Social-Psychological Analysis. New York: Holt, Rinehart \& Winston.

--- and A. I. TEGER (1969) "The risky shift in group betting." J. of Exper. Social Psychology 5: 115-136.

RAVEN, B. H. (1974) "The Nixon groups," presented at the annual meeting of the American Psychological Association, New Orleans. 
RETTIG, S. (1966) "Group discussion and predicted ethical risk taking." J, of Personality \& Social Psychology 3: 629-633.

RIKER, W. H. and P. C. ORDESHOOK (1973) An Introduction to Positive Political Theory. Englewood Cliffs, N.J.: Prentice-Hall.

ROBINSON, J. A. and R. A. MAJAK (1967) "A theory of decision-making," pp. 175-188 in J. C. Charlesworth (ed.) Contemporary Political Analysis. New York: Free Press.

ROIG, C. (1973) "Some theoretical problems in decision-making studies," pp. 19-54 in D. Sidjanski (ed.) Political Decision Making Processes. San Francisco: Jossey-Bass.

ROSENAU, J. N. (1967) "Premises and promises of decision-making analysis," pp. 189-212 in J. C. Charlesworth (ed.) Contemporary Political Analysis. New York: Free Press.

SCHICK, A. (1971) Budget Innovation in the States. Washington, D.C.: Brookings.

SCHOETTLE, E.C.B. (1968) "The state of the art in policy studies," pp. 149-179 in R. A. Bauer and K. J. Gergen (eds.) The Study of Policy Formation. New York: Free Press.

SCHROEDER, H. M., D. M. DRIVER, and S. STREUFERT (1967) Human Information Processing. New York: Holt, Rinehart \& Winston.

SCIOLI, F. A., J. W. DYSON, and D. W. FLEITAS (1971) "The relationship of personality and decisional structure to leadership." Presented at the National Conference of Public Administration, Denver, April.

SCOTT, W. (1967) Organizational Theory: A Behavioral Analysis for Management. Homewood, Ill: Irwin.

SHAPIRO, M. J. and M. BONHAM (1973) "Cognitive process and foreign policy decision making." International Studies Q. 17: 147-174.

SHERIF, M. and H. CANTRIL (1947) The Psychology of Ego Involvements. New York: John Wiley.

SIEGEL, S. (1957) "Level of aspiration and decision-making." Psych. Rev. 64: 253-262.

-- and L. E. FOURAKER (1960) Bargaining and Group Decision-Making. New York: McGraw-Hill.

SIGEL, R. S. (1964) "Effect of partisanship on the perception of political candidates." Public Opinion Q. 28: 483-496.

SIMON, H. A. (1958) Models of Man. New York: John Wiley.

-- (1957) Administrative Behavior (second ed.) New York: Free Press. (originally published in 1945)

SKJEI, S. S. (1973) Information for Collective Action. Lexington, Mass.: D. C. Heath.

SMITH, M. B. (1968) "A map for the analysis of personality and politics." J. of Social Issues 24: 15-28.

-..., J. BRUNER, and R. W. WHITE (1956) Opinions and Personality. New York: John Wiley.

SNYDER, R. C., H. W. BRUCK, and B. SAPIN (1962) "Decision-making as an approach to the study of international politics," pp. 14-186 in R. C. Snyder, H. W. Bruck, and B. Sapin (eds.) Foreign Policy Decision-Making: An Approach to the Study of International Politics. New York: Free Press. 
STOGDILL, R. M. (1974) Handbook of Leadership. New York: Free Press.

STONER, J.A.F. (1968) "Risky and cautious shifts in group decisions: the influence of widely held values." J. of Exper. Social Psychology 4: 442-459.

$---(1961)$ "A comparison of individual and group decisions involving risk." M.A. thesis, Massachusetts Institute of Technology.

STORING, H. J. (1962) "The science of administration: Herbert A. Simon," pp. 63-151 in H. J. Storing (ed.) Essays on the Scientific Study of Politics. New York: Holt, Rinehart \& Winston.

TAYLOR, D. W., P. C. BERRY, and C. H. BLOCK (1958) "Does group participation when using brainstorming facilitate or inhibit creative thinking?" Administrative Sci. Q. 3: 23-47.

TEGER, A. I. and D. G. PRUITT (1967) "Components of group risk taking." J. of Exper. Social Psychology 3: 189-205.

--- , R. ST. JEAN, and G. A. HAALAND (1970) "A reexamination of the familiarization hypothesis in group risk-taking." J. of Exper. Social Psychology 6: 346-350.

THIBAUT, J. W. and H. H. KELLEY (1959) The Social Psychology of Groups. New York: John Wiley.

VINOKUR, A. (1971a) "Cognitive and affective process influencing risk taking in groups: an expected utility approach." J. of Personality \& Social Psychology 20: $472-486$.

- - (1971b) "Review and theoretical analysis of the effects of group processes upon individual and group decisions involving risk." Psych. Bull. 58: 231-250.

WALKER, T. G. (1975) "Issues in the application of a risk-taking framework to political decision-making." Presented at the annual meeting of the International Studies Association, Washington, D.C.

-- and E. C. MAIN (1973) "Choice shifts in political decision-making: federal judges and civil liberties cases." J. of Applied Social Psychology 3: 39-48.

WALLACH, M. A. and N. KOGAN (1959) "Sex differences and judgment processes." J. of Personality 27: 555-564.

- - and D. J. BEM (1962) "Group influence on individual risk taking." Journal of Abnormal and Social Psychology 65: 75-86.

WALLACH, M. A., N. KOGAN, and R. B. BURT (1968) "Are risk-takers more persuasive than conservatives in group discussion?" J. of Exper. Social Psychology 4: 76-88.

WARR, P. B. and C. KNAPPER (1968) The Perception of People and Events. New York: John Wiley.

WEICK, K. E. (1965) "Laboratory experiments with organizations," pp. 194-260 in

J. G. March (ed.) Handbook of Organizations. Chicago: Rand McNally.

WHYTE, W. F. (1956) The Organization Man. New York: Simon \& Schuster.

WILDAVSKY, A. (1964) The Politics of the Budgetary Process. Boston: Little, Brown.

WILENSKY, H. L. (1967) Organizational Intelligence. New York: Basic Books.

WILKER, H. R. and L. W. MILBRATH (1970) "Political belief systems and political behavior." Social Sci. Q. 51: 477-493.

WILLIAMS, O. (1961) "Typology for comparative local government." Midwest J. of Pol. Sci. 5: 150-164. 
ZAJONC, R. B. (1965) "Social facilitation." Science 149: 269-274.

R. J. WOLOSIN, and M. A. WOLOSIN (1972) "Group risk-taking under various group decision schemes.” J. of Exper. Social Psychology 8: 16-30. 